\title{
The Clinical Usefulness of the Sentinel Lymph Node in Rectal Cancer: Do We Believe It?
}

\author{
Jong Woo Kim \\ Department of Surgery, Cha University School of Medicine, Seongnam, Korea
}

\section{See Article on Page 78-82}

The concept of sentinel lymph node (SLN) sampling for cancer is based on an orderly and sequential draining of lymphatic fluid from the primary tumor site via the lymphatic vessels and lymph nodes. Because of this pattern, the SLN as first draining lymph node is believed to filter and capture tumor cells, and conventional pathologic examination of the SLN is thought to be ideally able to recognize the presence and direction of tumor spread and allow the dissection scale to be determined and even the prognosis to be estimated. For example, as is well known, the SLN has been successfully playing an important role in the field of breast cancer, enabling unnecessarily wide dissections to be avoided, decreasing side effects and/or complications, preserving function as much as possible and finally improving the quality of life. Furthermore, it might contribute to improving the accuracy of staging and ultrastaging through investigations of micrometastasis or occult metastasis via selective techniques, such as cytokeratine immunohistochemistry or the reverse transcription polymerase chain reaction, in cases of node-negative patients $[1,2]$. As another example, in colon cancer, although the tumor status of the SLN may not change the extent of a resection because an en-bloc resection of the primary colon cancer includes regional lymph nodes, the results of SLN-based nodal ultra-staging in node-negative patients may improve identification of candidates for adjuvant therapy that is more effective for metastatic disease [3]. Thus, the SLN might be useful as another staging system, taking into account the biologic aspects of the tumor to identify patients with aggressive illness. Nevertheless, we shouldn't overlook either metastasis into regional or distant LNs jumping over the SLN or an aberrant direction of tumor

\section{Correspondence to: Jong Woo Kim, M.D.}

Department of Surgery, Bundang CHA Medical Center, Cha University School of Medicine, Yatap-dong, Bundang-gu, Seongnam 463-712, Korea

Tel: +82-31-780-5250, Fax: +82-31-780-5259

E-mail: kjw@cha.ac.kr

(C) 2011 The Korean Society of Coloproctology

This is an open-access article distributed under the terms of the Creative Commons Attribution NonCommercial License (http://creativecommons.org/licenses/by-nc/3.0) which permits unrestricted noncommercial use, distribution, and reproduction in any medium, provided the original work is properly cited. spread due to lymphatic blockage, in which case the establishment of the SLN concept seems to be not that easy $[4,5]$.

This paper is well organized only experimentally when it comes to the purpose of the study, but I doubt that this study contributes to the clinical usefulness of the SLN for rectal cancer treatment. We have different situations in rectal cancer that we should consider. First, the concept of a sentinel lymph in rectal cancer is still uncertain. Skipped metastasis or aberrant metastasis because of lymphatic channel occlusion or other causes, such as associated inflammation, preoperative radiation, etc., have been noted. Even very low rectal cancer needing coloanal anastomosis can uncommonly spread into the inguinal basin [6]. Second, unfortunately, the outcome and influence of micrometastasis, as one of the aims of this study, have not been definitely established for cancer prognosis in the node-negative group. We are still waiting for long-term outcomes. Third, even is sentinel LNs are identified and established, so far the treatment modality for rectal cancer has been already as surgery (total mesorectal excision or tumor related mesorectal excision), radiation and chemotherapy (FL) for both stage II and III cancers, and in my opinion, this treatment modality will not change until a newer, better treatment modality is identified or developed. Fourth, approximately $30 \%$ of rectal cancer patients have a positive regional LN at present, which means that the concept of a SLN is not meaningful in these patients. Thus, using the concept of the SLN might be time- and effort-consuming as a routine procedure, just showing the route of lymphatic drainage, and seems to have no clinical beneficial, except more careful check-ups for the patients with SLN micrometastasis in the node-negative group.

\section{REFERENCES}

1. Scabini S. Sentinel node biopsy in colorectal cancer: Must we believe it? World J Gastrointest Surg 2010;2:6-8.

2. van Wyk Q, Hosie KB, Balsitis M. Histopathological detection of lymph node metastases from colorectal carcinoma. J Clin Pathol 2000;53:685-7.

3. Bilchik AJ, Compton C. Close collaboration between surgeon and pathologist is essential for accurate staging of early colon cancer. Ann Surg 2007;245:864-6.

4. Berne TV, Donovan AJ. Synchronous anterior celiotomy and pos- 


\section{Coloproctology Jong Woo Kim}

terior drainage of pancreatic abscess. Arch Surg 1981;116:527-33.

5. Bembenek AE, Rosenberg R, Wagler E, Gretschel S, Sendler A, Siewert JR, et al. Sentinel lymph node biopsy in colon cancer: a prospective multicenter trial. Ann Surg 2007;245:858-63.
6. Damin DC, Tolfo GC, Rosito MA, Spiro BL, Kliemann LM. Sentinel lymph node in patients with rectal cancer invading the anal canal. Tech Coloproctol 2010;14:133-9. 